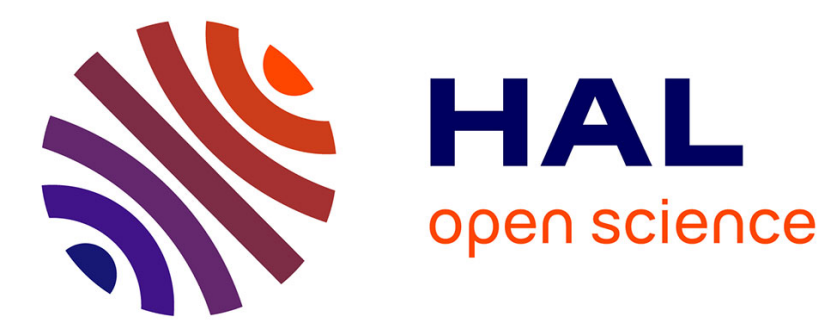

\title{
Pyrolysis of wood and PVC mixtures: thermal behaviour and kinetic modelling
}

Augustina Ephraim, Victor Pozzobon, Damien Lebonnois, Carlos Peregrina, Patrick Sharrock, Ange Nzihou, Doan Pham Minh

\section{- To cite this version:}

Augustina Ephraim, Victor Pozzobon, Damien Lebonnois, Carlos Peregrina, Patrick Sharrock, et al.. Pyrolysis of wood and PVC mixtures: thermal behaviour and kinetic modelling. Biomass Conversion and Biorefinery, inPress, 10.1007/s13399-020-00952-2 . hal-02920165

\section{HAL Id: hal-02920165 https://imt-mines-albi.hal.science/hal-02920165}

Submitted on 8 Oct 2020

HAL is a multi-disciplinary open access archive for the deposit and dissemination of scientific research documents, whether they are published or not. The documents may come from teaching and research institutions in France or abroad, or from public or private research centers.
L'archive ouverte pluridisciplinaire $\mathbf{H A L}$, est destinée au dépôt et à la diffusion de documents scientifiques de niveau recherche, publiés ou non, émanant des établissements d'enseignement et de recherche français ou étrangers, des laboratoires publics ou privés. 


\title{
Pyrolysis of wood and PVC mixtures: thermal behaviour and kinetic modelling
}

\author{
Augustina Ephraim ${ }^{1} \cdot$ Victor Pozzobon $^{2} \cdot$ Damien Lebonnois $^{3} \cdot$ Carlos Peregrina $^{3} \cdot$ Patrick Sharrock $^{1} \cdot$ Ange Nzihou $^{1}$. \\ Doan Pham Minh ${ }^{4,1}$ [D
}

\begin{abstract}
Wood waste containing halogenated compounds such as polyvinyl chloride (PVC) is in abundant supply, although the pyrolysis of such waste feedstock for energy production may cause corrosion and environmental problems due to the release of $\mathrm{HCl}$ gas. Hence, there is a need to understand the pyrolysis behaviour of chlorine-contaminated wood in order to develop methods that minimise the impact of chloride species on pyrolysis equipment and product quality. In literature, few studies exist on the kinetic analysis of wood and PVC co-pyrolysis. The existing models assume a single-step reaction with an $\mathrm{n}$-order reaction mechanism for the entire process, which may lead to large errors in the kinetic parameters estimated. Therefore, in this paper, we develop and validate a multi-step kinetic model that predicts the pyrolysis behaviour and reaction mechanism of poplar wood (PW) pellet with different contents of PVC $(0,1,5,10,100 \mathrm{wt} \%)$. Using data from thermogravimetric analysis of the pellets at heating rates of 5, 10 and $20^{\circ} \mathrm{C} / \mathrm{min}$, we determined the apparent kinetic parameters by combining Fraser-Suzuki deconvolution, isoconversional methods and master plot procedures. Our model fitted the experimental data well with a deviation of less than $4.5 \%$. Our results show that the addition of $1 \mathrm{wt} \%$ PVC to PW decreases the activation energy of hemicellulose and cellulose pyrolysis in PW from 136.3 to $101.6 \mathrm{~kJ} / \mathrm{mol}$ and from 216.7 to $108.2 \mathrm{~kJ} / \mathrm{mol}$, respectively. This demonstrates the importance of acid hydrolysis reactions between the cellulosic fibres of $\mathrm{PW}$ and $\mathrm{HCl}$ released from PVC dehydrochlorination. Furthermore, we found that a nucleation and growth mechanism best represents the rate-limiting interactions between PVC and PW, which we linked to the formation of metal chloride crystals from acid-base reactions between $\mathrm{HCl}$ and $\mathrm{PW}$ minerals. Our kinetic model is an improvement of current models for the co-pyrolysis of wood and PVC, and can be readily used in a reactor-scale model of a pyrolyser or gasifier due to its relative simplicity.
\end{abstract}

Keywords Waste $\cdot$ Co-pyrolysis $\cdot$ Wood $\cdot$ Polyvinyl chloride $\cdot$ Kinetic modelling $\cdot$ Reaction mechanism

Doan Pham Minh

phamminhdoan@duytan.edu.vn; doan.phamminh@mines-albi.fr

1 Université de Toulouse, IMT Mines Albi, UMR CNRS 5302, Centre RAPSODEE, Campus Jarlard, F-81013, cedex 09 Albi, France

2 LGPM, Centrale Supelec, Université Paris-Saclay, SFR Condorcet FR CNRS 3417, Centre Européen de Biotechnologie et de Bioéconomie (CEBB), 3 rue des Rouges Terres, 51110 Pomacle, France

3 SUEZ, 38, rue du Président Wilson, 78230 Le Pecq, France

4 Institute of Research and Development, Duy Tan University, Da Nang 550000, Vietnam

\section{Introduction}

Wood waste is an attractive feedstock for renewable energy production via pyrolysis/gasification, mainly due to its abundant supply, low recycling rate and good fuel properties [1]. Syngas generated from pyrolysis/gasification as the main product can be purified and upgraded into various valuable final products such as chemicals, biofuels and biomassderived hydrogen. As an example, Scheme 1 illustrates the main steps of biomass-derived hydrogen production from wood waste [2]. Purified syngas passes through water-gasshift (WGS) reactors under appropriate conditions to convert $\mathrm{CO}$ and steam into $\mathrm{H}_{2}$ and $\mathrm{CO}_{2}$ [3]. The mixture from WGS reactors' outlet is rich in $\mathrm{H}_{2}$. Pure biomass-derived hydrogen can be separated from this mixture by an operation like pressure-swing-adsorption (PSA) [2, 4]. 
Scheme 1 Main steps to produce biomass-derived hydrogen from wood waste

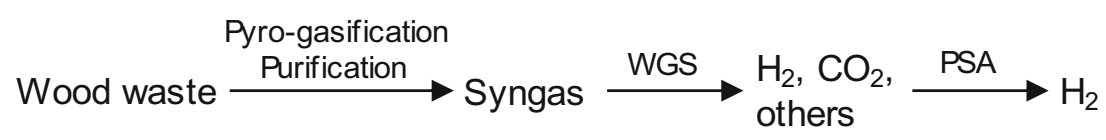

However, chemically treated wood waste with halogenated compounds such as polyvinyl chloride (PVC) may have significant chlorine content. In pyrolysers, chlorine in such waste readily vaporises at moderate temperatures $\left(>200{ }^{\circ} \mathrm{C}\right)$ to mainly form hydrogen chloride gas $(\mathrm{HCl})$, which causes corrosion, environmental damages and health-related problems. Dioxins could be also formed on solid surfaces at $200-400{ }^{\circ} \mathrm{C}$, and their formation is enhanced by the presence of chlorine compounds such as PVC [5]. Consequently, it is important to understand and predict the thermal decomposition behaviour of wood waste containing PVC in order to better control the hazardous impact of chloride species on pyrolysis systems and product quality.

In the last decade, several authors have studied the copyrolysis of PVC and different biomass/wastes using thermogravimetric analysis (TGA), and all have observed strong interactions in terms of lower pyrolysis temperatures of biomass/waste in the presence of PVC [6-13]. However, very few kinetic analyses of these interactions have been found in literature. A complete kinetic study of such a co-pyrolysis process requires the determination of the kinetic triplet: namely, the activation energy $\mathrm{E}$, the pre-exponential factor $A$, and the kinetic model $f(\alpha)[14]$.

Abdoulkas et al. [15] have studied the reactivity of copyrolysed olive residue and PVC using the isoconversional Friedman method to determine $E_{\alpha}$. The entire pyrolysis process was considered a single-step reaction which led to a significant variation of $E_{\alpha}$ with conversion $\alpha$. According to the Kinetics Committee of the International Confederation for Thermal Analysis and Calorimetry (ICTAC) [16], a significant variation of $E_{\alpha}$ with $\alpha$ indicates that the pyrolysis process is kinetically complex and thus, it is inappropriate to use a single-step rate equation to describe the kinetics of this process throughout the whole range of conversions and temperatures.

More recent kinetic analyses by Han et al. [8] and Çepelioğullara et al. [9] also suffer from this limitation of a single-step co-pyrolysis model. Furthermore, these models assume that the co-pyrolysis mechanism is firstorder $(f(\alpha)=1-\alpha)$ without reporting arguments that support this assumption. Recent works have proven that the pyrolysis of polymers does not necessarily take place through first- or $n$-order kinetics and that other mechanisms such as diffusion or random scission can control the decomposition reaction [17-19]. In such cases, this often yields higher $\mathrm{A}$ and $E_{\alpha}$ values than the true values and particularly give A values that are too large to be physically reasonable [17]. Other approaches such as distributed activation energy model (DAEM) are weak to interpret the reaction mechanism [20]. Facing such a problem, it is necessary to consider using other kinetic models $(f(\alpha))$ to fit the experimental data.

The objective of this work, therefore, is to develop a multi-step apparent kinetic model for the co-pyrolysis of PVC and poplar wood (PW) pellets and to identify the mechanisms that govern their interactions. This work combines the use of Fraser-Suzuki deconvolution and isoconversional Kissinger-Akahira-Sunose (KAS) methods to determine the apparent $E_{\alpha}$ for each pseudo-component in the $\mathrm{PVC} / \mathrm{PW}$ mixture, as well as the master-plot procedure to determine the reaction mechanisms $f(\alpha)$, and eventually A. Deconvolution allows identifying the peak of each species from a global signal, while isoconversional method is related to the investigation of a transformation at the same conversion, by changing a parameter (e.g. heating rate in this work).

\section{Thermal analysis method}

\subsection{Preparation of poplar wood-PVC pellets}

The PW sample used in this study was obtained from Special Diets Services (SDS). It was first dried at 105 ${ }^{\circ} \mathrm{C}$ for $24 \mathrm{~h}$ and then ground into fine powder with a particle size $<100 \mu \mathrm{m}$. The PVC samples were provided by Analytic Lab with a particle size of approximately $130 \mu \mathrm{m}$. To prepare 0, 1, 5, 10 and $100 \mathrm{wt} \% \mathrm{PVC} /$ PW pellets, the samples were first weighed and then mixed using pestle and mortar. The mixture was then pressed manually at 10 bar to produce $500 \mathrm{mg}$ pellets of $<3 \mathrm{~mm}$ thickness. Table 1 shows the proximate and ultimate analysis of the PW and PVC samples as well as their major inorganic element composition.

\subsection{Thermogravimetric apparatus and procedure}

Thermogravimetric analysis of the samples was performed under atmospheric pressure using a TGA/DTA analyser (STA 409 PC, Netzsch). Samples of $500 \mathrm{mg}$ were placed in platinum crucibles and heated from 30 to $800{ }^{\circ} \mathrm{C}$ at rates of 5,10 and $20{ }^{\circ} \mathrm{C} / \mathrm{min}$ under nitrogen atmosphere $(100 \mathrm{~mL} / \mathrm{min})$. Each heating rate run was repeated twice and the mass loss data were found to be repeatable (error $<1 \%$ ). 

ultimate and major inorganic ash element analysis of poplar wood (PW) and PVC
Table 1 Proximate,

\begin{tabular}{lcc}
\hline Sample & PW & PVC \\
\hline \multicolumn{2}{l}{ Proximate analysis (wt $\%$, ar) } & \\
Moisture & 8.4 & 0.0 \\
Ash & 2.0 & 0.0 \\
Volatiles & 85.1 & 95.8 \\
Fixed carbon & 4.5 & 4.2 \\
Ultimate analysis (wt $\%$, daf) & \\
$\mathrm{C}$ & 49.9 & 38.7 \\
$\mathrm{H}$ & 6.4 & 4.8 \\
$\mathrm{O}$ & 42.7 & 0.0 \\
$\mathrm{~N}$ & 1.0 & 0.0 \\
$\mathrm{~S}$ & 0.00 & 0.0 \\
$\mathrm{Cl}$ & 0.01 & 56.5 \\
$\mathrm{Major}$ inorganic ash elements $(\mathrm{ppm}, \mathrm{ar})$ \\
$\mathrm{Ca}$ & 3981 & 0.0 \\
$\mathrm{~K}$ & 655 & 0.0 \\
$\mathrm{Na}$ & 382 & 0.0 \\
$\mathrm{Mg}$ & 384 & 0.0 \\
$\mathrm{P}$ & 340 & 0.0 \\
\hline
\end{tabular}

\section{Thermal analysis results}

\subsection{Pyrolysis of pure poplar wood and PVC}

Figure 1a shows the TG/DTG curves for the pyrolysis of $100 \mathrm{wt} \% \mathrm{PW}$ at heating rates of 5,10 and $20^{\circ} \mathrm{C} / \mathrm{min}$. These curves show the typical behaviour of wood pyrolysis: a shoulder appears at $190-290{ }^{\circ} \mathrm{C}$ which corresponds to hemicellulose decomposition; a sharp peak is observed at $290-360{ }^{\circ} \mathrm{C}$ owing to cellulose decomposition; and the broad, low magnitude tailing at $360-500{ }^{\circ} \mathrm{C}$ can be linked to lignin degradation [21].

Concerning the pyrolysis of PVC, three main degradation steps could be observed in Fig. 1b. The first step, which occurs at $200-350{ }^{\circ} \mathrm{C}$, is the dehydrochlorination of PVC to form

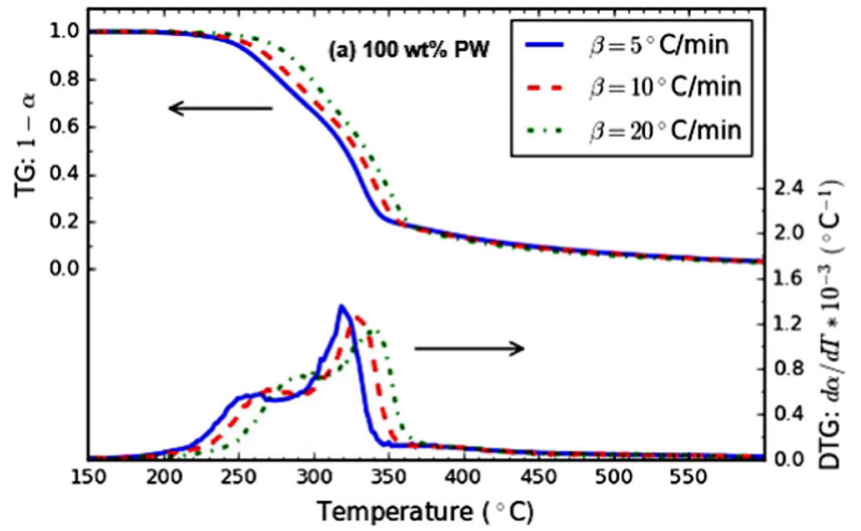

$\mathrm{HCl}$ and polyene. In the second step $\left(300-350{ }^{\circ} \mathrm{C}\right)$, the polyene molecules produced subsequently undergo condensation and de-alkylation reactions to form benzene and aromatic compounds, e.g. $\mathrm{C}_{6} \mathrm{H}_{6}, \mathrm{C}_{10} \mathrm{H}_{10}, \mathrm{C}_{8} \mathrm{H}_{9} \mathrm{Cl}$, and $\mathrm{C}_{18} \mathrm{H}_{15} \mathrm{Cl}[22$, 23]. Finally, above $350{ }^{\circ} \mathrm{C}$, cyclisation and cross-linking of polyene molecules occur to form polyaromatic hydrocarbons $(\mathrm{PAH})$ and char residues $[22,23]$.

The effect of the heating rate can be seen in Fig. 1 for both PW and PVC. As the heating rate increases, the TG/DTG curves shift towards higher temperatures. This phenomenon has also been observed in other literature works involving TGA $[24,25]$ and is due to heat transfer limitations resulting from the temperature difference between the sample and the furnace. In such instances, the thermal lag is more pronounced at higher heating rates, which in turn slows down the decomposition rate. Even though this phenomenon can be observed, it is thought to have only a minor impact on our model results (maximum deviation of $4.5 \%$, cf. Table 5 and Table 6).

\subsection{Co-pyrolysis of PVC and poplar wood}

Figure 2 presents the TG/DTG curves for the pyrolysis of 1, 5 and $10 \mathrm{wt} \% \mathrm{PVC} / \mathrm{PW}$ pellet samples at heating rates of 5, 10 and $20{ }^{\circ} \mathrm{C} / \mathrm{min}$. By comparing these TG/DTG curves to those of $100 \mathrm{wt} \% \mathrm{PW}$ and PVC in Fig. 1, the following observations can be made:

- The presence of PVC shifts the DTG peaks of hemicellulose and cellulose decomposition in wood towards lower temperatures. For example, at a heating rate of $5{ }^{\circ} \mathrm{C} / \mathrm{min}$, cellulose in pure wood degrades with a DTG peak at approximately $332{ }^{\circ} \mathrm{C}$. However, in the presence of 1,5 and $10 \mathrm{wt} \% \mathrm{PVC}$, this temperature is lowered by 2, 55, and 60 ${ }^{\circ} \mathrm{C}$, respectively. These lower temperatures thus approach the DTG peak temperature of PVC dehydrochlorination $\left(266^{\circ} \mathrm{C}\right)$.

- With respect to pure wood, the addition of PVC significantly increases the height of the DTG peaks at 200-300

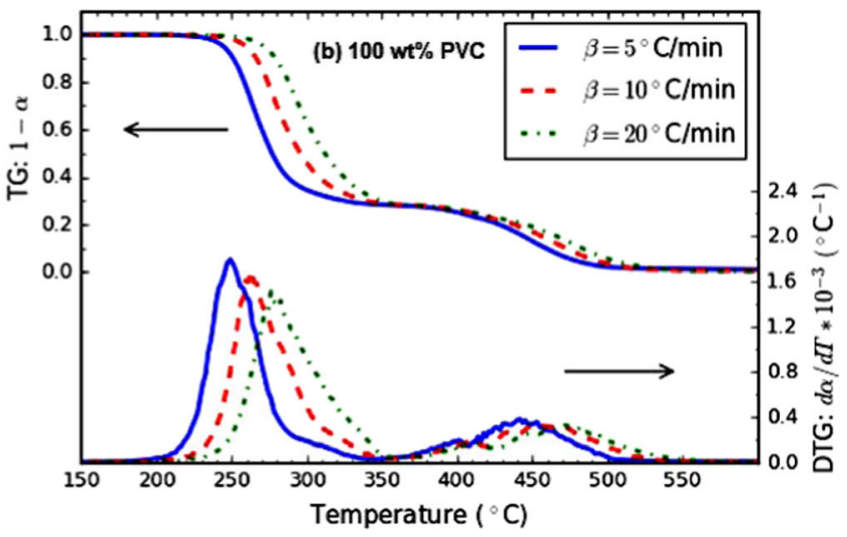

Fig. 1 TG and DTG curves of a pure poplar wood (PW) and $\mathbf{b}$ and PVC pellets at heating rates of 5, 10 and $20^{\circ} \mathrm{C} / \mathrm{min}$ 

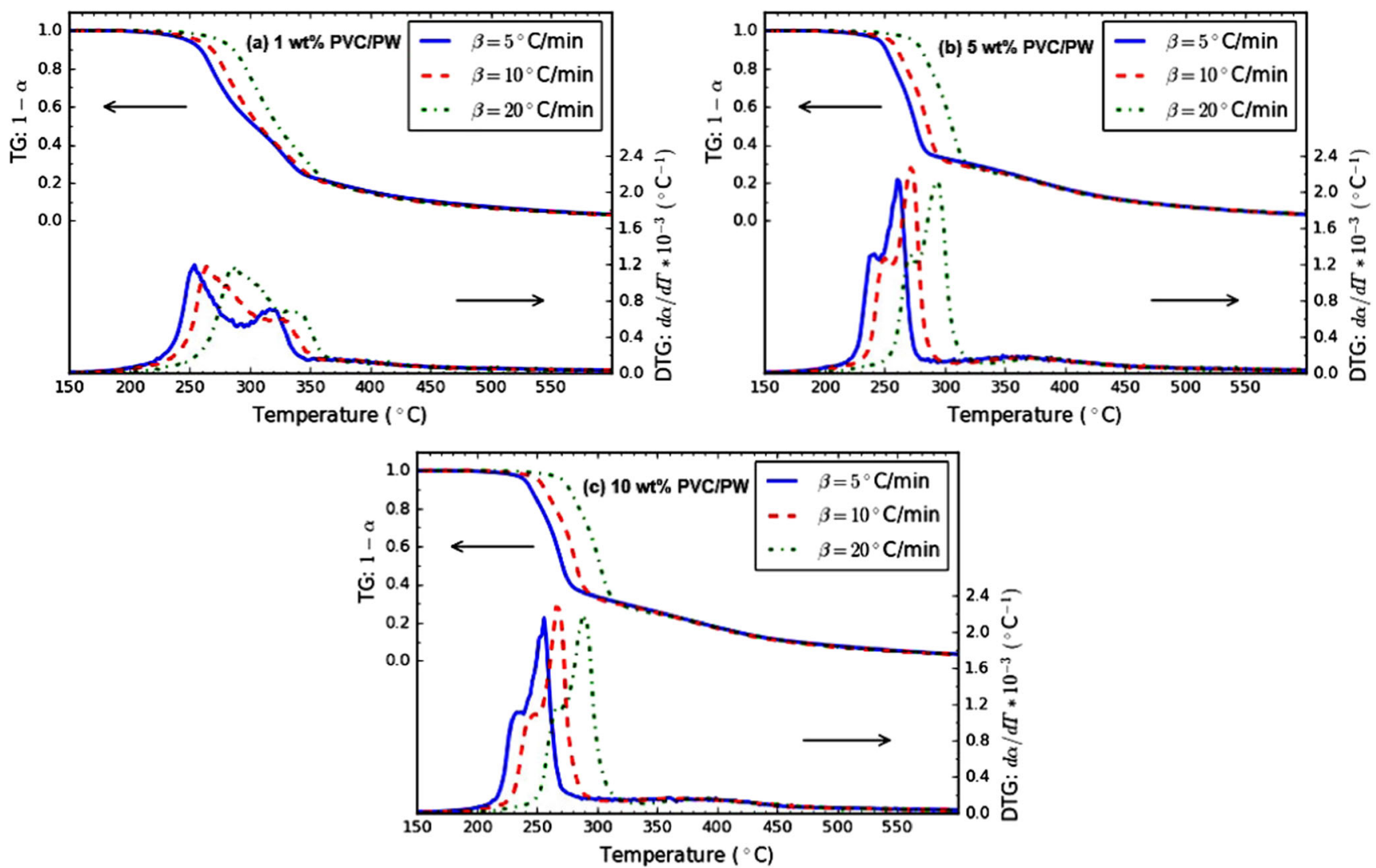

Fig. 2 TG and DTG curves of pellets of a $1 \mathrm{wt} \%$, b $5 \mathrm{wt} \%$, and c $10 \mathrm{wt} \% \mathrm{PVC} /$ poplar wood (PW) pellets at heating rates of 5,10 and $20{ }^{\circ} \mathrm{C} / \mathrm{min}$

${ }^{\circ} \mathrm{C}$, which relates to cellulosic fibre degradation. For instance, at a heating rate of $5^{\circ} \mathrm{C} / \mathrm{min}$, the corresponding DTG peak heights for 1,5 and $10 \mathrm{wt} \%$ PVC increase by a factor of 2.10, 3.77 and 3.80, respectively, compared with pure wood pyrolysis. Furthermore, in the case of $5 \mathrm{wt} \%$ and $10 \mathrm{wt} \% \mathrm{PVC} / \mathrm{PW}$ samples, the DTG peak heights increase by a factor of 1.19 and 1.20 respectively compared with pure PVC pyrolysis.

- At temperatures between 350 and $500{ }^{\circ} \mathrm{C}$, the conversion of $10 \mathrm{wt} \% \mathrm{PVC} / \mathrm{PW}$ is only $4 \%$ more than that of $100 \mathrm{wt} \%$ $\mathrm{PW}$. Hence, lignin in PW can be considered largely unaffected by the cyclisation/cross-linking step in PVC pyrolysis.

The above observations are indicative of the strong interaction between the cellulosic components of $\mathrm{PW}$ and $\mathrm{HCl}$ released during PVC dehydrochlorination.

Another point worth noting is the very small difference in the pyrolysis behaviour of 5 and $10 \mathrm{wt} \% \mathrm{PVC} / \mathrm{PW}$.

This implies that most, if not all, of the cellulosic fibres in wood react with the chlorinated species products during copyrolysis with $\mathrm{PVC}$ concentrations as low as $5 \mathrm{wt} \%$. $\mathrm{HCl}$ released from dehydrochlorination of $\mathrm{PVC}$ has been considered a catalyst of cellulosic fibre degradation $[6,8]$. However, this is not the case for $1 \mathrm{wt} \%$ PVC, because a second DTG peak corresponding to cellulose decomposition appears at roughly $330^{\circ} \mathrm{C}$ (Fig. 2) and thus, not all the cellulose decomposes during the dehydrochlorination step. Matsuzawa et al. [13] also observed a second DTG peak at approximately 300 ${ }^{\circ} \mathrm{C}$ for a mixture of $2 \mathrm{wt} \% \mathrm{PVC}$ and a pure cellulose polymer.

\section{Kinetic modelling approach}

\subsection{Model assumptions and reaction scheme}

To describe the TG/DTG curves of pure poplar wood, a threecomponent devolatilisation mechanism is proposed for the volatile fractions of its pseudo-components, hemicellulose $(\mathrm{H})$, cellulose $(\mathrm{C})$ and lignin $(\mathrm{L})$. These pseudo-components decompose independently of each other as shown by Eq. 1 to Eq. 3.

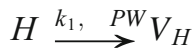

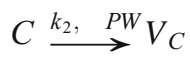
$L \stackrel{k_{3}, \quad P W}{\longrightarrow} V_{L}$ 
where $k$ refers to the reaction rate constant and $V$ is the gas released from each devolatilisation reaction. Some mineral matter in wood may also volatilise during pyrolysis, but they generally make up a small mass fraction of wood and are therefore not considered in this reaction scheme. A threecomponent mechanism is also proposed for PVC, involving the pseudo-components, $\mathrm{HCl}$ and polyene $(P)$, as expressed by Eq. 4 to Eq. 6 :

$$
\begin{aligned}
& H C l \stackrel{k_{1}, P V C}{\longrightarrow} V_{H C l} \\
& P 1 \stackrel{k_{2}, P V C}{\longrightarrow} V_{P 1} \\
& P 2 \stackrel{k_{3}, P V C}{\longrightarrow} V_{P 2}
\end{aligned}
$$

where $P 1$ refers to the polyene molecules that volatilise as a result of condensation and de-alkylation reactions, and $P 2$ are the polyene molecules that degrade by cyclisation and crosslinking reactions.

A global reaction scheme is also proposed for the interactions between the pseudo-components of PW and PVC during co-pyrolysis (Eq. 7 to Eq. 12). Here, only the dehydrochlorination phase in PVC pyrolysis is considered, which, for convenience sake, is represented by the volatilisation of $\mathrm{HCl}$ pseudo-component. Hemicellulose and cellulose in PW decompose to release volatiles via two parallel reactions: thermal degradation and acid hydrolysis. Finally, lignin only undergoes thermal degradation because it mainly decomposes after $\mathrm{HCl}$ release.

$$
\begin{aligned}
& H \stackrel{k_{1}, \quad P V C / P W}{\longrightarrow} V_{H} \\
& C \stackrel{k_{2}, \quad P V C / P W}{\longrightarrow} V_{C} \\
& \mathrm{~L} \stackrel{k_{3}, \quad P V C / P W}{\longrightarrow} V_{L} \\
& \mathrm{HCl} \stackrel{k_{4}, \quad P V C / P W}{\longrightarrow} V_{H C l} \\
& \mathrm{H}-\mathrm{HCl} \stackrel{k_{5}, \quad P V C / P W}{\longrightarrow} V_{H-H C l} \\
& \mathrm{C}-\mathrm{HCl} \stackrel{k_{6}, \quad P V C / P W}{\longrightarrow} V_{C-H C l}
\end{aligned}
$$

With regard to modelling $1 \mathrm{wt} \% \mathrm{PVC} / \mathrm{PW}$ pyrolysis, all six reactions in Eq. 7 to Eq. 12 are assumed to take place, thus leading to a six-pseudo-component devolatilisation model. However, for 5 and $10 \mathrm{wt} \% \mathrm{PVC} / \mathrm{PW}$, a four-pseudocomponent model is considered because the hydrolysis rate of hemicellulose and cellulose is expected to be much faster than the thermal degradation rate in the presence of high $\mathrm{HCl}$ concentrations. Thus, in the case of high PVC concentrations ( 5 or $10 \mathrm{wt} \%$ ), reactions 1 and 2 (or 7 and 8 ) are assumed to be negligible.

\subsection{TGA kinetics}

The expression for the rate of solid-state reactions has the following form: $\frac{d(\alpha)}{d t}=k(T) f(\alpha)$

The conversion, $\alpha$, is the fraction of the initial sample decomposed:

$\alpha=\frac{m_{o}-m}{m_{o}-m_{\infty}}$

where $m_{o}$ and $m_{\infty}$ are the initial and final mass of the sample, and $m$ is the mass at a given time $t$ of the analysis. According to the Arrhenius equation, the temperature dependence on the rate constant, $k$, is given by:

$k=A \exp \left(\frac{-E}{R T}\right)$

where $A$ is the pre-exponential factor $\left(\mathrm{min}^{-1}\right), E$ is the activation energy $(\mathrm{kJ} / \mathrm{mol}), R$ is the gas constant $(8.314 \mathrm{~J} / \mathrm{K} / \mathrm{mol})$ and $T$ is the absolute temperature (K). Combining Eq. 13 and Eq. 15 gives the fundamental expression (Eq. 16) to determine the kinetic parameters that satisfactorily describe the TGA results:

$\frac{d \alpha}{d t}=A \exp \left(\frac{-E}{R T}\right) f(\alpha)$

For non-isothermal TGA experiments at linear heating rate, $\beta=d T / d t$; thus, Eq. 16 can be expanded to:

$\frac{d \alpha}{d T}=\left(\frac{A}{\beta}\right) \exp \left(\frac{-E}{R T}\right) f(\alpha)$

\subsection{Fraser-Suzuki deconvolution}

Deconvolution of the DTG peaks can be performed using a Fraser-Suzuki function (FSF) [25].

$\left.\frac{d \alpha}{d T}\right|_{i}=H_{p, i} \exp \left\{-\frac{\ln 2}{A_{s, i}^{2}} \ln \left[1+2 A_{s, i} \frac{T-T_{p, i}}{W_{h f, i}}\right]^{2}\right\}$

The FSF parameters, $H_{p}, A_{s}, T_{p}$, and $W_{h f}$, represent height $\left(\mathrm{K}^{-1}\right)$, asymmetry (dimensionless), peak temperature $(\mathrm{K})$ and half-width (K) of the $d \alpha / d T$ versus $T$ profile for the $i$ th pseudocomponent respectively. Hence, for wood and PVC pyrolysis, the deconvolution of the $d \alpha / d T$ versus $T$ profile gives:

$\frac{d \alpha}{d T}=\sum_{i=1}^{N_{c}} c_{i} H_{p, i} \exp \left\{-\frac{\ln 2}{A_{s, i}^{2}} \ln \left[1+2 A_{s, i} \frac{T-T_{p, i}}{W_{h f, i}}\right]^{2}\right\}$

where $c_{i}$ and $N_{c}$ are the mass fraction of the $i$ th pseudocomponent and the total number of pseudo-components of each sample respectively. To estimate the unknown parameters, $c_{i}, H_{p}, A_{s}, T_{p}$, and $W_{h f}$ were initially guessed and then 
adjusted until the deviation between the calculated and experimental values for $d \alpha / d T$ was minimised. The deviation $\operatorname{Dev}(\%)$ was calculated using nonlinear least squares [25]:

$\operatorname{Dev}(\%)=\frac{\sqrt{\left(\sum_{j=1}^{N_{d}}\left[\left(\frac{d \alpha}{d T}\right)_{j, e}-\left(\frac{d \alpha}{d T}\right)_{j, c}\right]^{2}\right) / N_{d}}}{h}$

where $j$ denotes the $j$ th experimental point and $N_{d}$ is the total number of data points. $(d \alpha / d T)_{j, c}$ and $(d \alpha / d T)_{j, e}$ are the calculated and experimental DTG data, and $h$ is the maximum value of $d \alpha / d T$. Note that the calculated DTG data is the sum of all the deconvoluted peaks.

Next, the separated $d \alpha / d T$ curves were each integrated using the middle Riemann sum method [26] to obtain $\alpha$ values for each component $i$ :

$\alpha_{i}=\sum_{j=1}^{N_{d}} \frac{1}{2}\left[\left(\frac{d \alpha}{d T}\right)_{j}+\left(\frac{d \alpha}{d T}\right)_{j-1}\right]\left(T_{j}-T_{j-1}\right)$

\subsection{Activation energy determination using KAS method}

The integral rearrangement of Eq. 16 gives:

$g(\alpha)=\int_{0}^{\alpha} \frac{1}{f(\alpha)} d \alpha=\frac{A}{\beta} \int_{T_{o}}^{T} \exp \left(\frac{-E}{R T}\right) d T$

where $g(\alpha)$ is the integral form of $f(\alpha)$. $f(\alpha)$ is a function for the algebraic expression that represents the mechanism of the solid-degradation process. The most common forms of $f(\alpha)$ and corresponding $g(\alpha)$ are listed in Table 2.

Kissinger-Akahira-Sunose (KAS) method [16] linearises Eq. 22 to obtain the following expression:

$\ln \left(\frac{\beta}{T_{\alpha}^{2}}\right)=\ln \left(\frac{A_{\alpha} R}{E_{\alpha} g(\alpha)}\right)-\frac{-E}{R T_{\alpha}}$

The apparent activation energy can be obtained from the plot of $\ln \left(\beta / T_{\alpha}^{2}\right)$ versus $1000 / T_{\alpha}$ for a given value of conversion, $\alpha$, where the slope of the straight line is equal to $-E_{\alpha} / R$. Once the most suitable $f(\alpha)$ is known, the pre-exponential factor, $A_{\alpha}$, can be calculated from the intercept.

\subsection{Master plots}

The most suitable reaction mechanism of pyrolysis, $f(\alpha)$, can be determined using the generalised master plots method [15].

$\lambda(\alpha)=\frac{f(\alpha)}{f(\alpha)_{0.5}}=\frac{(d \alpha / d t)_{\alpha}}{(d \alpha / d t)_{0.5}} \frac{\exp \left[E_{o} / R T_{\alpha}\right]}{\exp \left[E_{o} / R T_{0.5}\right]}$

where $(d \alpha / d t)_{0.5}$ and $T_{0.5}$ are the conversion rate and temperature corresponding to $\alpha=0.5$, respectively. $E_{o}$ is the average activation energy determined using the KAS method. The suitable pyrolysis reaction mechanism is obtained when the model $\lambda(\alpha)$ best matches the experimental $\lambda(\alpha)$.
Table 2 The most common reaction mechanism functions used in kinetic analysis of solidstate reactions $[25,27,28]$

\begin{tabular}{llll}
\hline Model & & $f(\alpha)=(1 / k)(d \alpha / d t)$ & $g(\alpha)=k t$ \\
\hline Power law & Pn Power law & $n(\alpha)^{(n-1) / n}$ & $\alpha^{1 / n}$ \\
Nucleation and growth & A2 Avrami-Erofeev & $2(1-\alpha)[-\ln (1-\alpha)]^{1 / 2}$ & {$[-\ln (1-\alpha)]^{1 / 2}$} \\
& A3 Avrami-Erofeev & $3(1-\alpha)[-\ln (1-\alpha)]^{2 / 3}$ & {$[-\ln (1-\alpha)]^{1 / 3}$} \\
& A4 Avrami-Erofeev & $4(1-\alpha)[-\ln (1-\alpha)]^{3 / 4}$ & {$[-\ln (1-\alpha)]^{1 / 4}$} \\
& B1 Prout-Trompkins & $\alpha(1-\alpha)$ & $\ln (\alpha /(1-\alpha))$ \\
Geometrical models & R2 contracting area & $2(1-\alpha)^{1 / 2}$ & $1-(1-\alpha)^{1 / 2}$ \\
& R3 contracting volume & $3(1-\alpha)^{2 / 3}$ & $1-(1-\alpha)^{1 / 3}$ \\
Diffusion models & D1 one-dimensional & $1 / 2 \alpha$ & $\alpha^{2}$ \\
& D2 two-dimensional & {$[-\ln (1-\alpha)]^{-1}$} & $(1-\alpha) \ln (1-\alpha)+\alpha$ \\
& D3 three-dimensional & $3 / 2(1-\alpha)^{2 / 3}\left[1-(1-\alpha)^{1 / 3}\right]$ & $1-\left((1-\alpha)^{1 / 3}\right)^{2}$ \\
& D4 Ginstling-Brounshein & $3 / 2\left[(1-\alpha)^{-1 / 3}-1\right]^{-1}$ & $1-(2 \alpha / 3)-(1-\alpha)^{2 / 3}$ \\
Order-based models & F0 zero order & 1 & $\alpha$ \\
& F1 first order & $1-\alpha$ & $-\ln (1-\alpha)$ \\
& F2 second order & $(1-\alpha)^{2}$ & {$[1 /(1-\alpha)]-1$} \\
& F3 third order & $(1-\alpha)^{3}$ & {$\left[1 /(1-\alpha)^{2}\right]-1$} \\
Random scission model & L2 & $2\left(\alpha^{1 / 2}-\alpha\right)$ & - \\
\hline
\end{tabular}

$g(\alpha)$ is the integral form of $f(\alpha)$ 


\section{Kinetic modelling results}

\subsection{Fraser-Suzuki deconvolution results}

The Fraser-Suzuki deconvolution parameters for pure PW and PVC pyrolysis at 5, 10 and $20^{\circ} \mathrm{C} / \mathrm{min}$ are listed in Table 3, and those for 1, 5 and $10 \mathrm{wt} \%$ PVC/PW mixtures are shown in Table 4. The deconvolution models fit the experimental data satisfactorily with low deviation values $(<4 \%)$ which were calculated using Eq. 20. Figure 3 gives an example of the deconvolution curves of the samples at a heating rate of $5{ }^{\circ} \mathrm{C} / \mathrm{min}$.

\subsection{Isoconversional activation energy results}

Following the separation of the DTG peaks (Fig. 3), the middle Riemann sum integral method (Eq. 21) was employed to obtain the conversion values $\alpha$, with respect to temperature for each pseudo-component at all three heating rates $(5,10,20$ ${ }^{\circ} \mathrm{C} / \mathrm{min}$ ). Next, the isoconversional activation energy of each pseudo-species decomposition was evaluated at a given $\alpha$ from the slope of the KAS plot in Eq. 23, i.e. $\ln \left(\beta / T_{\alpha}^{2}\right)$ versus $1 / T_{\alpha}$ plot. As an example, Fig. 4 presents the KAS plots for all six components of $1 \mathrm{wt} \% \mathrm{PVC} / \mathrm{PW}$ in the conversion range of 0.10 to 0.90 . Correlation coefficient values $\left(R^{2}\right)$ ranging between 0.9900 and 1 were obtained from linear regression analysis of these plots, which indicates that the activation energies calculated are relatively accurate.

Figure 5 displays the evolution of activation energy $\left(E_{\alpha}\right)$ with conversion $\alpha$, calculated for the pseudo-components of pure PW and PVC as well as their mixtures. According to the ICTAC Kinetics Committee [16], $E_{\alpha}$ values are considered to vary significantly with $\alpha$ if the difference between the maximum and minimum values of $E_{\alpha}$ is above $20-30 \%$ of the average $E_{\alpha}$. From Fig. 5, it can be observed that $E_{\alpha}$ values for the co-pyrolysis pseudo-species $(\mathrm{H}-\mathrm{HCl}$ and $\mathrm{C}-\mathrm{HCl})$ and those of pure $\mathrm{PVC}(\mathrm{HCl}, \mathrm{P} 1$ and $\mathrm{P} 2)$, are roughly constant with variations of $<16 \%$ over the entire conversion range. Thus, it is likely that the decomposition of each of these pseudo-components is dominated by a single reaction mechanism and can therefore be adequately described by a singlestep model [16]. However, higher $E_{\alpha}$ variations with $\alpha$ can be observed for hemicellulose (29\%), cellulose (22\%) and lignin
Table 3 Fraser-Suzuki deconvolution results for pure $\mathrm{PW}$ and $\mathrm{PVC}$ at 5, 10 and 20 ${ }^{\circ} \mathrm{C} / \mathrm{min}$

\begin{tabular}{|c|c|c|c|c|c|c|c|}
\hline \multicolumn{2}{|c|}{ Component } & \multicolumn{3}{|c|}{$100 \mathrm{wt} \% \mathrm{PM}$} & \multicolumn{3}{|c|}{$100 \mathrm{wt} \% \mathrm{PVC}$} \\
\hline & & $5^{\circ} \mathrm{C} / \mathrm{min}$ & $10^{\circ} \mathrm{C} / \min$ & $20^{\circ} \mathrm{C} / \mathrm{min}$ & $5^{\circ} \mathrm{C} / \mathrm{min}$ & $10^{\circ} \mathrm{C} / \mathrm{min}$ & $20^{\circ} \mathrm{C} / \mathrm{min}$ \\
\hline \multirow[t]{5}{*}{$\mathrm{H}$} & $H_{p}$ & 0.51 & 0.53 & 0.58 & - & - & - \\
\hline & $T_{p}^{p}$ & 275 & 287.75 & 300.5 & - & - & - \\
\hline & $\stackrel{p}{W_{h f}}$ & 53 & 53 & 51 & - & - & - \\
\hline & $A_{s}$ & -0.06 & -0.10 & -0.10 & - & - & - \\
\hline & $c_{i}$ & 0.33 & 0.34 & 0.35 & - & - & - \\
\hline \multirow[t]{5}{*}{$\mathrm{C}$} & $H_{p}$ & 1.30 & 1.20 & 1.1 & - & - & - \\
\hline & $T_{p}$ & 332 & 341.75 & 351.9 & - & - & - \\
\hline & $W_{h f}$ & 25 & 27 & 29 & - & - & - \\
\hline & $A_{s}$ & -0.40 & -0.40 & -0.40 & - & - & - \\
\hline & $c_{i}$ & 0.42 & 0.41 & 0.41 & - & - & - \\
\hline \multirow[t]{5}{*}{$\mathrm{L}$} & $H_{p}$ & 0.11 & 0.105 & 0.1 & - & - & - \\
\hline & $T_{p}^{p}$ & 371.5 & 380.5 & 391 & - & - & - \\
\hline & $W_{h f}$ & 185 & 190 & 195 & - & - & - \\
\hline & $A_{s}$ & 0.20 & 0.31 & 0.45 & - & - & - \\
\hline & $c_{i}$ & 0.25 & 0.25 & 0.24 & - & - & - \\
\hline \multirow[t]{5}{*}{$\mathrm{HCl}$} & $H_{p}$ & - & - & - & 1.60 & 1.55 & 1.4 \\
\hline & $T_{p}$ & - & - & - & 266 & 279.5 & 293 \\
\hline & $W_{h f}$ & - & - & - & 33 & 33 & 33 \\
\hline & $A_{s}$ & - & - & - & 0.00 & 0 & 0 \\
\hline & $c_{i}$ & - & - & - & 0.55 & 0.57 & 0.56 \\
\hline \multirow[t]{5}{*}{ P1 } & $H_{p}$ & - & - & - & 0.3 & 0.3 & 0.33 \\
\hline & $T_{p}^{p}$ & - & - & - & 290 & 306 & 322 \\
\hline & $W_{h f}$ & - & - & - & 50 & 50 & 50 \\
\hline & $A_{s}$ & - & - & - & 0.2 & 0.2 & 0.2 \\
\hline & $c_{i}$ & - & - & - & 0.16 & 0.16 & 0.18 \\
\hline \multirow[t]{5}{*}{ P2 } & $H_{p}$ & - & - & - & 0.35 & 0.3 & 0.28 \\
\hline & $T_{p}$ & - & - & - & 447 & 460 & 473 \\
\hline & $\stackrel{p}{W_{h f}}$ & - & - & - & 77.5 & 85 & 85 \\
\hline & $A_{s}$ & - & - & - & 0 & 0 & 0 \\
\hline & $c_{i}$ & - & - & - & 0.29 & 0.28 & 0.26 \\
\hline \multicolumn{2}{|c|}{$\operatorname{Dev}(\%)$} & 1.99 & 1.63 & 2.23 & 1.48 & 1.99 & 2.85 \\
\hline
\end{tabular}


Table 4 Fraser-Suzuki deconvolution results for of 1,5 and $10 \mathrm{wt} \% \mathrm{PW} / \mathrm{PVC}$ pellets at 5,10 and $20^{\circ} \mathrm{C} / \mathrm{min}$

\begin{tabular}{|c|c|c|c|c|c|c|c|c|c|c|}
\hline \multicolumn{2}{|c|}{ Component } & \multicolumn{3}{|c|}{$1 \mathrm{wt} \% \mathrm{PVC} / \mathrm{PW}$} & \multicolumn{3}{|c|}{$5 \mathrm{wt} \% \mathrm{PVC} / \mathrm{PW}$} & \multicolumn{3}{|c|}{$10 \mathrm{wt} \% \mathrm{PVC} / \mathrm{PW}$} \\
\hline & & $5^{\circ} \mathrm{C} / \mathrm{min}$ & $10^{\circ} \mathrm{C} / \mathrm{min}$ & $20^{\circ} \mathrm{C} / \mathrm{min}$ & $5^{\circ} \mathrm{C} / \min$ & $10^{\circ} \mathrm{C} / \mathrm{min}$ & $20^{\circ} \mathrm{C} / \mathrm{min}$ & $5^{\circ} \mathrm{C} / \mathrm{min}$ & $10^{\circ} \mathrm{C} / \mathrm{min}$ & $20^{\circ} \mathrm{C} / \mathrm{min}$ \\
\hline \multirow[t]{5}{*}{$\mathrm{H}$} & $H_{p}$ & 0.16 & 0.18 & 0.2 & - & - & - & - & - & - \\
\hline & $T_{p}$ & 275 & 287.75 & 300.5 & - & - & - & - & - & - \\
\hline & $W_{h f}$ & 53 & 53 & 51 & - & - & - & - & - & - \\
\hline & $A_{s}$ & -0.06 & -0.1 & -0.1 & - & - & - & - & - & - \\
\hline & $c_{i}$ & 0.11 & 0.12 & 0.13 & - & - & - & - & - & - \\
\hline \multirow[t]{5}{*}{$\mathrm{C}$} & $H_{p}$ & 0.72 & 0.63 & 0.67 & - & - & - & - & - & - \\
\hline & $T_{p}$ & 332 & 341.75 & 351.5 & - & - & - & - & - & - \\
\hline & $W_{h f}$ & 25 & 27 & 29 & - & - & - & - & - & - \\
\hline & $A_{s}$ & -0.4 & -0.4 & -0.4 & - & - & - & - & - & - \\
\hline & $c_{i}$ & 0.25 & 0.23 & 0.26 & - & - & - & - & - & - \\
\hline \multirow[t]{5}{*}{$\mathrm{L}$} & $H_{p}$ & 0.11 & 0.1 & 0.1 & 0.16 & 0.14 & 0.14 & 0.15 & 0.14 & 0.14 \\
\hline & $T_{p}$ & 371.5 & 380.5 & 391 & 371.5 & 380.5 & 391 & 371.5 & 380.5 & 391 \\
\hline & $W_{h f}$ & 185 & 190 & 195 & 185 & 190 & 195 & 185 & 190 & 195 \\
\hline & $A_{s}$ & 0.2 & 0.31 & 0.45 & 0.2 & 0.31 & 0.45 & 0.2 & 0.31 & 0.45 \\
\hline & $c_{i}$ & 0.27 & 0.25 & 0.24 & 0.35 & 0.32 & 0.35 & 0.34 & 0.33 & 0.33 \\
\hline \multirow[t]{5}{*}{$\mathrm{HCl}$} & $H_{p}$ & 0.0128 & 0.0134 & 0.014 & 0.0735 & 0.073 & 0.0724 & 0.137 & 0.136 & 0.143 \\
\hline & $T_{p}$ & 266 & 279.5 & 293 & 266 & 279.5 & 293 & 266 & 279.5 & 293 \\
\hline & $W_{h f}$ & 33 & 33 & 33 & 33 & 33 & 33 & 33 & 33 & 33 \\
\hline & $A_{s}$ & 0 & 0 & 0 & 0 & 0 & 0 & 0 & 0 & 0 \\
\hline & $c_{i}$ & 0.0055 & 0.0056 & 0.0056 & 0.0282 & 0.0289 & 0.0283 & 0.0552 & 0.0555 & 0.0559 \\
\hline \multirow[t]{5}{*}{$\mathrm{H}-\mathrm{HCl}$} & $H_{p}$ & 0.9 & 0.93 & 0.93 & 1.1 & 1.1 & 1.1 & 0.95 & 0.95 & 1 \\
\hline & $T_{p}$ & 267 & 280 & 298.5 & 255 & 268.5 & 286 & 250 & 264 & 282 \\
\hline & $W_{h f}$ & 20 & 20 & 20 & 20 & 20 & 20 & 20 & 20 & 20 \\
\hline & $A_{s}$ & 0 & 0 & 0 & 0 & 0 & 0 & 0 & 0 & 0 \\
\hline & $c_{i}$ & 0.23 & 0.23 & 0.22 & 0.25 & 0.26 & 0.26 & 0.22 & 0.22 & 0.24 \\
\hline \multirow[t]{5}{*}{$\mathrm{C}-\mathrm{HCl}$} & $H_{p}$ & 0.59 & 0.72 & 0.7 & 2 & 2 & 2 & 1.95 & 2 & 2 \\
\hline & $T_{p}$ & 284 & 301 & 318 & 275 & 288 & 307 & 270 & 283 & 303 \\
\hline & $W_{h f}$ & 16 & 16 & 16 & 16 & 16 & 16 & 16 & 16 & 16 \\
\hline & $A_{s}$ & 0 & 0 & 0 & 0 & 0 & 0 & 0 & 0 & 0 \\
\hline & $c_{i}$ & 0.13 & 0.15 & 0.14 & 0.38 & 0.39 & 0.38 & 0.39 & 0.39 & 0.38 \\
\hline \multicolumn{2}{|l|}{$\operatorname{Dev}(\%)$} & 3.9 & 3.9 & 3.1 & 1.8 & 2.3 & 1.4 & 1.7 & 1.8 & 1.2 \\
\hline
\end{tabular}

$(35 \%)$ in pure PW as they are more kinetically complex. Because the pyrolysis of lignin takes place over several stages, and its decomposition occurs over a wide temperature range, it would therefore be more appropriate to apply multi-step kinetics to treat this process. However, this lies beyond the scope of the current work and, thus, some loss of accuracy in lignin decomposition kinetics will be tolerated in order to favour reliable kinetic predictions of the interactions between the cellulosic pseudo-components of $\mathrm{PW}$ and $\mathrm{HCl}$ from PVC.

The average apparent activation energies obtained for cellulose, hemicellulose and lignin in PW are 216, 136 and 112 $\mathrm{kJ} / \mathrm{mol}$ respectively. These results fall within the range of activation energies in literature for biomass pseudo-components, as summarised in a recent review by Anca-Couce [29]. For
PVC, the pseudo-species, $\mathrm{HCl}, \mathrm{P} 1$ and $\mathrm{P} 2$, have an average $E_{\alpha}$ of 120,112 , and $226 \mathrm{~kJ} / \mathrm{mol}$. Similar to biomass pyrolysis, literature values for the activation energy of PVC vary considerably, possibly due to the different temperature programs used and the type of PVC sample studied. For example, Sanchez-Jimenez et al. [30] have reported an $E_{\alpha}$ of $114 \mathrm{~kJ} /$ mol for HCl-PVC whereas Miranda et al. [31] have obtained $198 \mathrm{~kJ} / \mathrm{mol}$. However, the trend in activation energies for the three pseudo-components agrees with those generally found in literature : $E_{\alpha, P 1}<E_{\alpha, H C l}<E_{\alpha, P 2}$ [31-33]. Furthermore, the co-pyrolysis pseudo-components, $\mathrm{H}-\mathrm{HCl}$ and $\mathrm{C}-\mathrm{HCl}$, have average $E_{\alpha}$ values of 97.9 and $101.7 \mathrm{~kJ} / \mathrm{mol}$ respectively which are lower than those obtained for their pure-sample counterparts. This observed catalytic effect of $\mathrm{HCl}$ on 

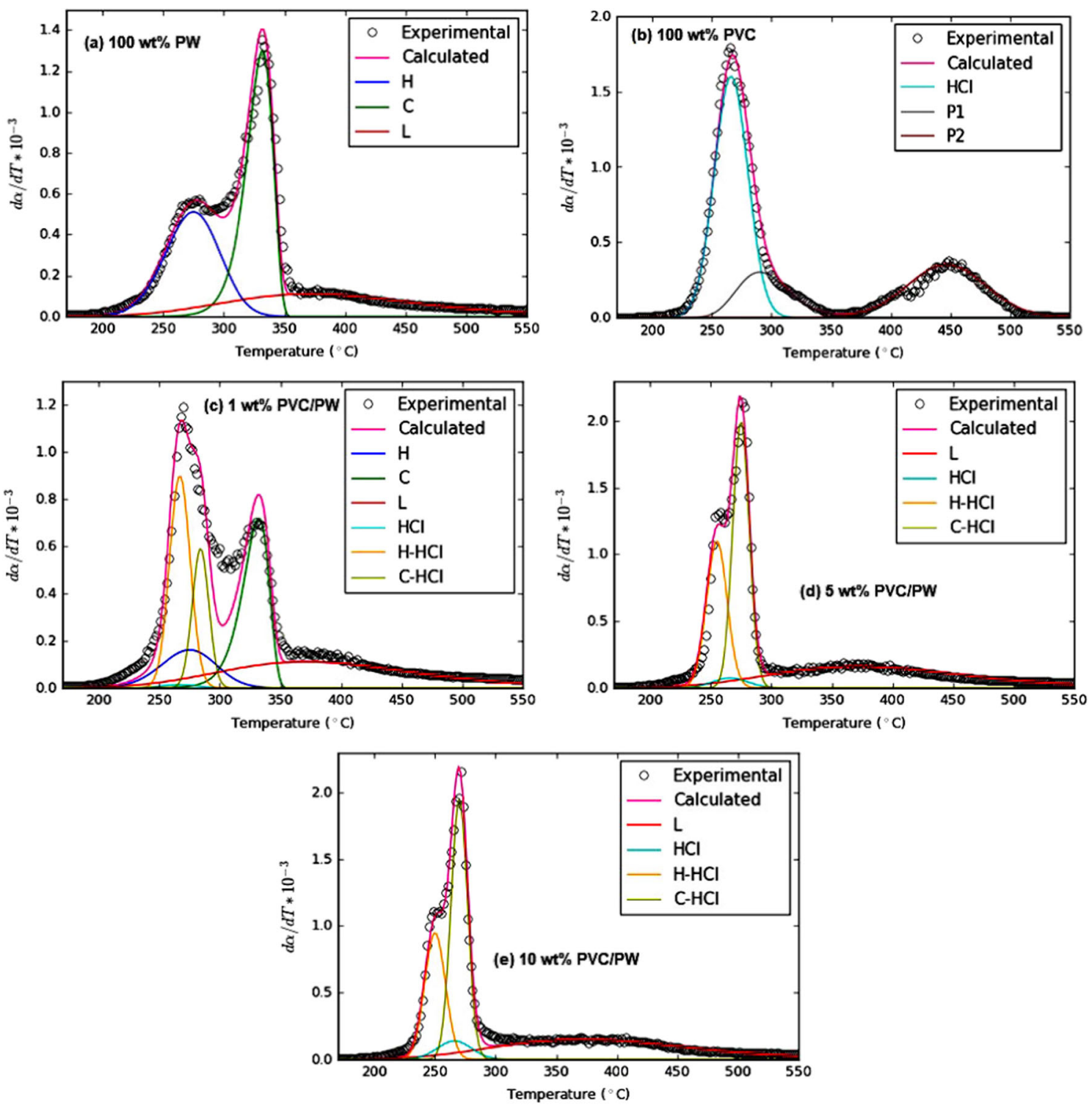

Fig. 3 Deconvoluted DTG curves of pellets of a poplar wood (PW), b PVC, c $1 \mathrm{wt} \% \mathrm{PVC} / \mathrm{PW}, \mathbf{d} 5 \mathrm{wt} \% \mathrm{PVC} / \mathrm{PW}$, and e $10 \mathrm{wt} \% \mathrm{PVC} / \mathrm{PW}$ at $5{ }^{\circ} \mathrm{C} / \mathrm{min}$

cellulosic fibres is supported by the experimental work of Matsuzawa et al. [13] who have shown that $\mathrm{HCl}$ evolution from PVC catalyses the dehydration and charring of cellulose to form $\mathrm{H}_{2} \mathrm{O}, \mathrm{CO}, \mathrm{CO}_{2}$, char and other volatiles. In addition, new findings show that the depolymerisation of cellulose to produce levoglucosan during pyrolysis can be catalysed by $\mathrm{H}_{2} \mathrm{O}$ or neighbouring $\mathrm{OH}^{-}$groups $[17,34,35]$. Hence, $\mathrm{HCl}$ can also indirectly catalyse cellulose depolymerisation via the formation of more $\mathrm{H}_{2} \mathrm{O}$ from the dehydration process.

\subsection{Master plots for kinetic model determination}

Figure 6 shows the theoretical master plots of the kinetic models listed in Table 2, as well as the master plots of experimental data corresponding to each pseudo-component. Based on these master plots, the following suitable models have been identified.

Order-based $(F)$ models best describe pseudo hemicellulose $(H)$, lignin $(L), P 1$ and $P 2$ pyrolysis. An order-based model with a reaction order other than $n=0,1,2$ and 3 , is semi-empirical in solid-state kinetics, and hence, it may be a combined effect of other mechanisms such as nucleation and diffusion as is the case for hemicellulose pyrolysis [20,36]. A reaction order of $n=1.4$ was obtained for hemicellulose decomposition which is identical to the recently published result by Wang et al. [20] and also falls within the range, $n=1-2$, reported in literature $[19,37,38]$. As for pseudo-lignin, a high reaction order between $n=4$ and $n=5$ was reached when matched with the experimental results. This behaviour of lignin may be linked to its highly complex phenylpropane composition whose degradation may involve several mechanisms 

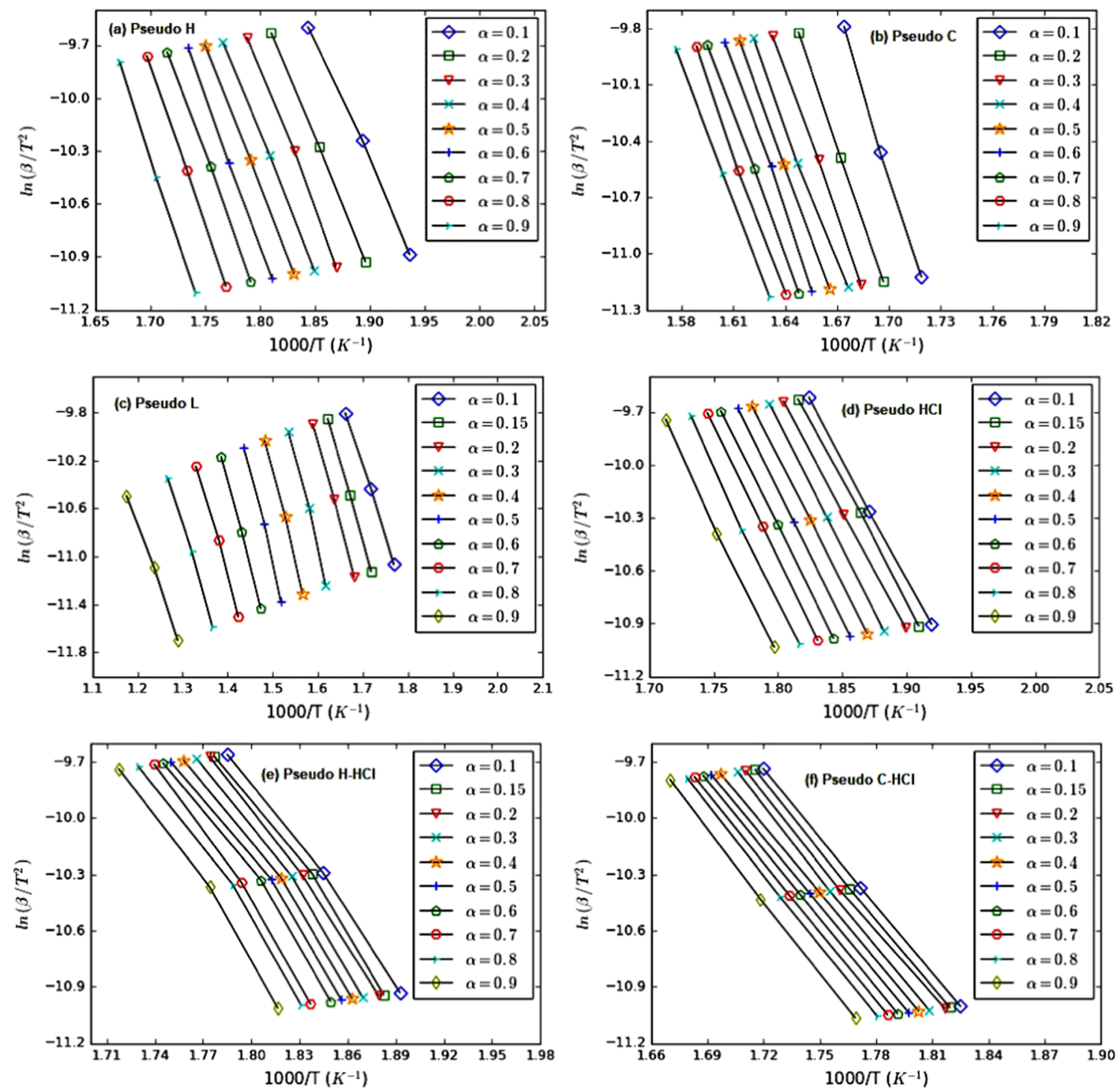

Fig. 4 KAS plots for the pseudo-components between conversions of 0.1 and 0.9

occuring simultaneously. Furthermore, for $P 1$ and $P 2$, reaction orders of $n=1$ and $n=2.5$ can be observed. Solid-state kinetic mechanisms for these two pseudo-components have not yet been found in literature in order to compare with our results.

The Random scission (L2) function most adequately models cellulose $(C)$ and $\mathrm{HCl}$ degradation. Random scission is an "acceleratory" type model which assumes that bond breaking occurs randomly along the polymer chains, producing fragments of progressively shorter length that eventually evaporate when they are small enough $[18,39]$. This mechanism for cellulose pyrolysis has recently been reported by several authors [15-17, $40]$ and can be associated with intra-ring scission of the glucose unit in the cellulose chain during dehydration and charring reactions [13]. Regarding pseudo $\mathrm{HCl}-$ PVC decomposition via dehydrochlorination, the observed random scission mechanism may stem from $\beta$-scission reactions that occur along the polymer chain leading to the reduction in chain length and the formation of polyene molecules [27].

Avrami-Erofeev (A) equations best model $\mathrm{H}-\mathrm{HCl}$ and $\mathrm{C}$ - $\mathrm{HCl}$ pseudo-components. An Avrami-Erofeev model is also an "acceleratory" type model and is based on nucleation and growth of crystals formed from chemical reactions [28, 41]. Both pseudo $\mathrm{H}-\mathrm{HCl}$ and $\mathrm{C}-\mathrm{HCl}$ have an $\mathrm{n}$ value of 2 , representing two-dimensional growth of crystal nuclei, assuming that the number of nuclei remains constant. This A2 reaction mechanism for $\mathrm{H}-\mathrm{HCl}$ and $\mathrm{C}-\mathrm{HCl}$ decomposition signals a rate-limiting acid-base reaction between $\mathrm{HCl}$ and minerals in wood (Table 1) to form metal chloride salt crystals (e.g. $\mathrm{CaCl}_{2}, \mathrm{NaCl}$ and $\mathrm{KCl}$ ).

A summary of the kinetic model results for PW, PVC and PVC/PW pyrolysis is presented in Table 5 and Table 6. 

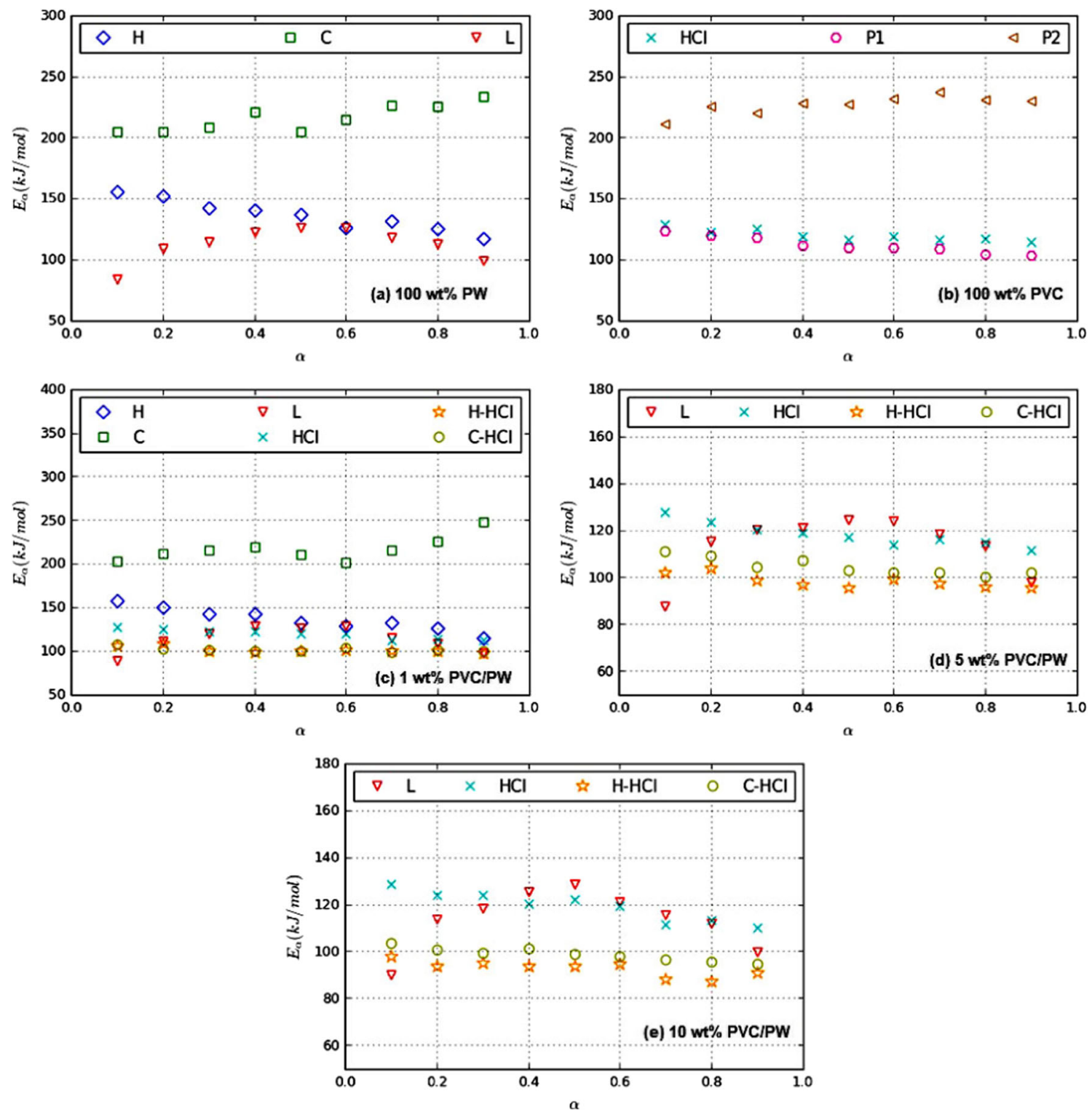

Fig. 5 Activation energy distribution as a function of conversion of the pseudo-components in a poplar wood (PW), b PVC, $\mathbf{c} 1 \mathrm{wt} \% \mathrm{PVC} / \mathrm{PW}, \mathbf{d} 5 \mathrm{wt} \%$ $\mathrm{PVC} / \mathrm{PW}$, and e $10 \mathrm{wt} \% \mathrm{PVC} / \mathrm{PW}$

With regard to pseudo-lignin (L), a new kinetic model, F3*: $f(\alpha)=(1-\alpha)^{2.9577} \alpha^{-0.008}$, was determined using the nonlinear least squares regression and the Evolutionary Solver in Excel to fit the experimental data via minimising the deviation parameter in Eq. 20. The optimal pre-exponential factors A were also determined using this method. It can be seen in Table 5 and Table 6 that the deviation between the predicted DTG data and the experimental ones is less than $4.5 \%$ for all samples, which is considered to be a good agreement.

\section{Conclusion}

The work presented in this paper deals with the development and validation of a multi-step kinetic model that predicts the pyrolysis behaviour and reaction mechanism of poplar wood pellets with different contents of PVC. Thermogravimetric experiments at different heating rates were conducted, and apparent kinetic parameters were determined by combining Fraser-Suzuki deconvolution, isoconversional ("model-free") methods and master plot procedures. Our model fits the experimental data well with a deviation of less than $4.5 \%$.

The model results show that at a low PVC concentration of $1 \mathrm{wt} \%$, the apparent activation energies of the pseudocomponents of PW, hemicellulose and cellulose, decrease from 136.3 to $101.6 \mathrm{~kJ} / \mathrm{mol}$ and from 216.7 to $108.2 \mathrm{~kJ} / \mathrm{mol}$, respectively. Moreover, increasing the concentration of PVC by a factor of 5 and 10 further decreases the activation energy of hemicellulose by $2.8 \mathrm{~kJ} / \mathrm{mol}$ and $8.3 \mathrm{~kJ} / \mathrm{mol}$ and that of cellulose by 3.6 and $9.5 \mathrm{~kJ} / \mathrm{mol}$, respectively. The observed 


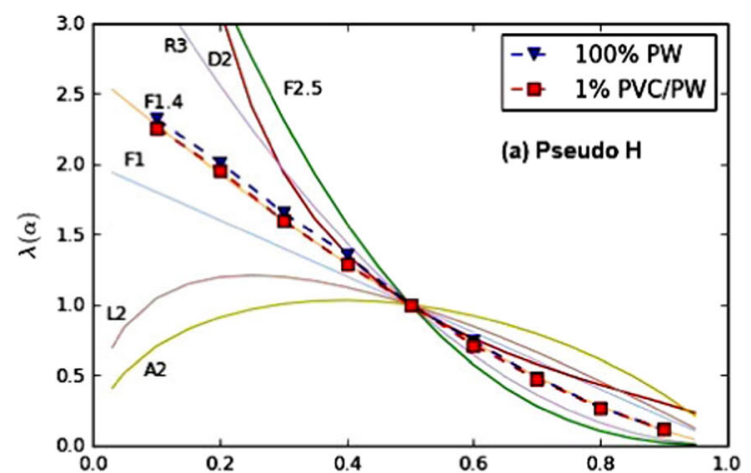

(a)

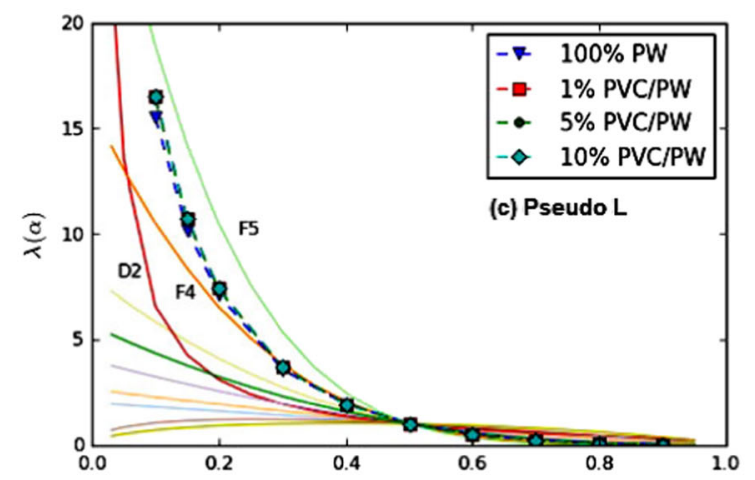

(a)

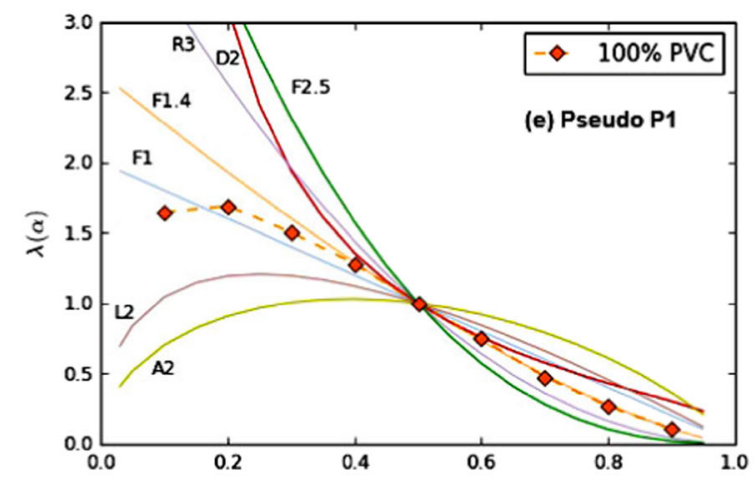

(a)

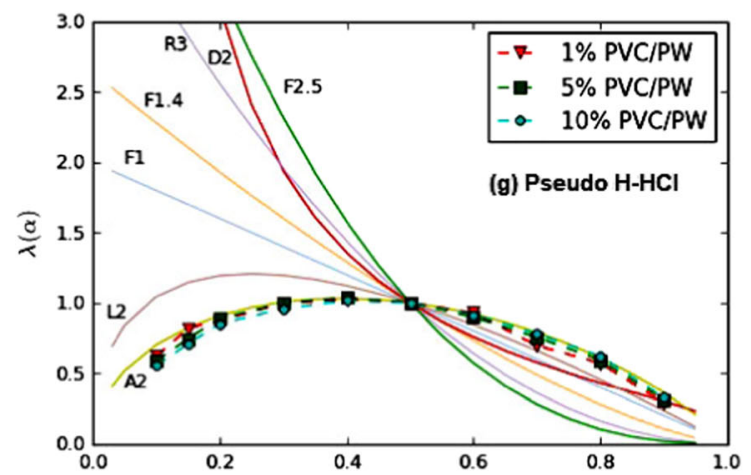

(a)

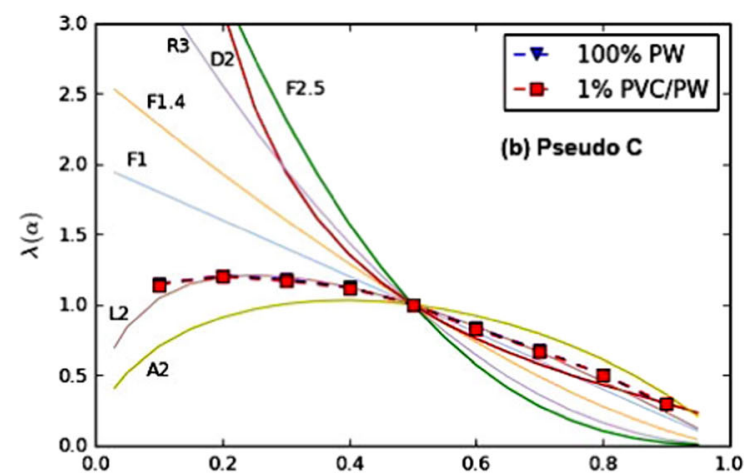

(a)

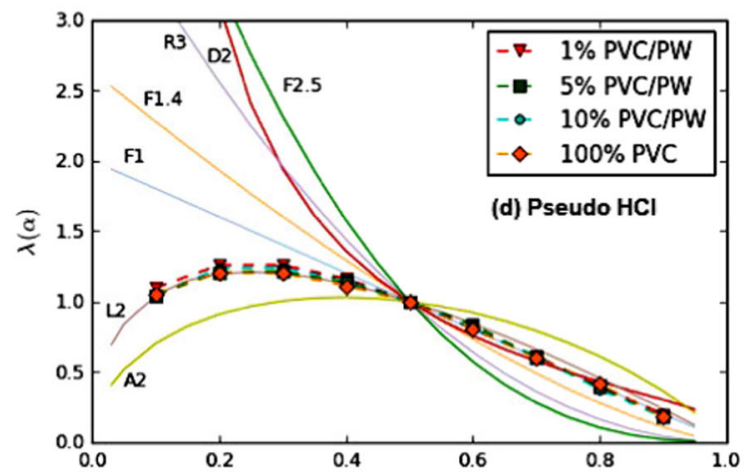

(a)

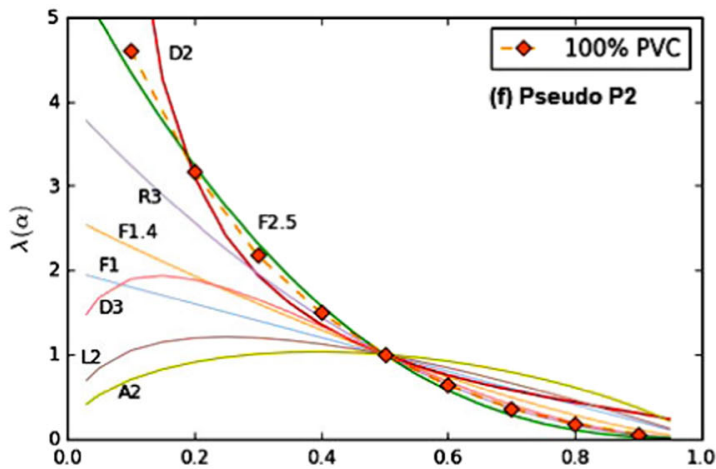

(a)

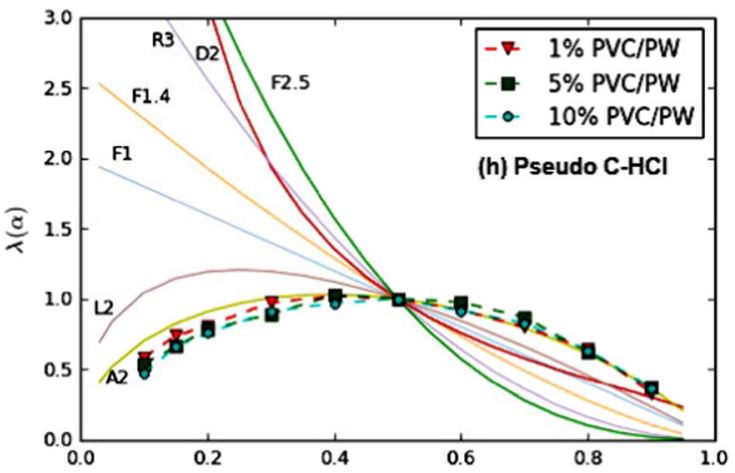

(a)

Fig. 6 Comparisons between experimental and theoretical mechanistic models according to the generalised master plot procedure

decrease in activation energies is due to acid hydrolysis of the cellulosic fibres by $\mathrm{HCl}$ which is formed from the dehydrochlorination of PVC during pyrolysis.
The reaction mechanism or rate-limiting step for the interaction between PVC and PW was identified to be a nucleation and growth mechanism that follows the 
Table 5 Kinetic parameters for the pyrolysis of pure PW and PVC pellets. Values have been averaged over heating rates of 5,10 and $20{ }^{\circ} \mathrm{C} / \mathrm{min}$

\begin{tabular}{|c|c|c|c|}
\hline Component & & $100 \mathrm{wt} \% \mathrm{PW}$ & $100 \mathrm{wt} \% \mathrm{PVC}$ \\
\hline \multirow[t]{4}{*}{$\mathrm{H}$} & $\mathrm{E}(\mathrm{kJ} / \mathrm{mol})$ & 136.2 & - \\
\hline & $\mathrm{A}\left(\mathrm{min}^{-1}\right)$ & $7.7 \times 10^{13}$ & - \\
\hline & Model & $\mathrm{F} 1.4$ & - \\
\hline & $\mathrm{c}$ & 0.37 & - \\
\hline \multirow[t]{4}{*}{$\mathrm{C}$} & $\mathrm{E}(\mathrm{kJ} / \mathrm{mol})$ & 215.9 & - \\
\hline & $\mathrm{A}\left(\min ^{-1}\right)$ & $8.3 \times 10^{19}$ & - \\
\hline & Model & $\mathrm{L} 2$ & - \\
\hline & $\mathrm{c}$ & 0.42 & - \\
\hline \multirow[t]{4}{*}{$\mathrm{L}$} & $\mathrm{E}(\mathrm{kJ} / \mathrm{mol})$ & 110.7 & - \\
\hline & $\mathrm{A}\left(\mathrm{min}^{-1}\right)$ & $2.7 \times 10^{9}$ & - \\
\hline & Model & $\mathrm{F} 3 *$ & - \\
\hline & $\mathrm{c}$ & 0.24 & - \\
\hline \multirow[t]{4}{*}{$\mathrm{HCl}$} & $\mathrm{E}(\mathrm{kJ} / \mathrm{mol})$ & - & 119.7 \\
\hline & $A\left(\min ^{-1}\right)$ & - & $7.5 \times 10^{12}$ \\
\hline & Model & - & L2 \\
\hline & $\mathrm{c}$ & - & 0.56 \\
\hline \multirow[t]{4}{*}{ P1 } & $\mathrm{E}(\mathrm{kJ} / \mathrm{mol})$ & - & 112.2 \\
\hline & $\mathrm{A}\left(\min ^{-1}\right)$ & - & $6.8 \times 10^{10}$ \\
\hline & Model & - & $\mathrm{F} 1$ \\
\hline & $\mathrm{c}$ & - & 0.23 \\
\hline \multirow[t]{4}{*}{$\mathrm{P} 2$} & $\mathrm{E}(\mathrm{kJ} / \mathrm{mol})$ & - & 225.9 \\
\hline & $\mathrm{A}\left(\mathrm{min}^{-1}\right)$ & - & $2.5 \times 10^{17}$ \\
\hline & Model & - & $\mathrm{F} 2.5$ \\
\hline & $\mathrm{c}$ & - & 0.21 \\
\hline $\operatorname{Dev}(\%)$ & & 4.1 & 3.2 \\
\hline
\end{tabular}

$\mathrm{F} 3^{*}: f(\alpha)=(1-\alpha)^{2.9577} \alpha^{-0.008}$

Avrami-Erofeev model with $n=2(A 2)$. This kinetic model has been linked to the formation and growth of metal chloride crystals as a result of acid-base reactions between $\mathrm{HCl}$ and minerals in $\mathrm{PW}$.
Table 6 Kinetic parameters for the pyrolysis of $\mathrm{PVC} / \mathrm{PW}$ pellets. Values have been averaged over heating rates of 5, 10 and 20 ${ }^{\circ} \mathrm{C} / \mathrm{min}$

\begin{tabular}{|c|c|c|c|c|}
\hline Component & & $1 \mathrm{wt} \% \mathrm{PVC} / \mathrm{PW}$ & $5 \mathrm{wt} \% \mathrm{PVC} / \mathrm{PW}$ & $10 \mathrm{wt} \% \mathrm{PVC} / \mathrm{PW}$ \\
\hline \multirow[t]{4}{*}{$\mathrm{H}$} & $\mathrm{E}(\mathrm{kJ} / \mathrm{mol})$ & 136.3 & - & - \\
\hline & $\mathrm{A}\left(\min ^{-1}\right)$ & $2.6 \times 10^{13}$ & - & - \\
\hline & Model & F1.4 & - & - \\
\hline & $\mathrm{c}$ & 0.12 & - & - \\
\hline \multirow[t]{4}{*}{$\mathrm{C}$} & $\mathrm{E}(\mathrm{kJ} / \mathrm{mol})$ & 216.7 & - & - \\
\hline & $\mathrm{A}\left(\min ^{-1}\right)$ & $5.6 \times 10^{19}$ & - & - \\
\hline & Model & $\mathrm{L} 2$ & - & - \\
\hline & $\mathrm{c}$ & 0.25 & - & - \\
\hline \multirow[t]{4}{*}{$\mathrm{L}$} & $\mathrm{E}(\mathrm{kJ} / \mathrm{mol})$ & 112.6 & 112.2 & 112.6 \\
\hline & $\mathrm{A}\left(\min ^{-1}\right)$ & $3.6 \times 10^{9}$ & $5.4 \times 10^{9}$ & $5.5 \times 10^{9}$ \\
\hline & Model & F3* & $\mathrm{F} 3 *$ & $\mathrm{~F} 3 *$ \\
\hline & $\mathrm{c}$ & 0.21 & 0.29 & 0.29 \\
\hline \multirow[t]{4}{*}{$\mathrm{HCl}$} & $\mathrm{E}(\mathrm{kJ} / \mathrm{mol})$ & 120.1 & 119 & 119.9 \\
\hline & $\mathrm{A}\left(\min ^{-1}\right)$ & $6.4 \times 10^{10}$ & $3.2 \times 10^{11}$ & $7.5 \times 10^{11}$ \\
\hline & Model & $\mathrm{L} 2$ & $\mathrm{~L} 2$ & $\mathrm{~L} 2$ \\
\hline & $\mathrm{c}$ & 0.0053 & 0.0301 & 0.0583 \\
\hline \multirow[t]{4}{*}{$\mathrm{H}-\mathrm{HCl}$} & $\mathrm{E}(\mathrm{kJ} / \mathrm{mol})$ & 101.6 & 98.8 & 93.3 \\
\hline & $A\left(\min ^{-1}\right)$ & $3.8 \times 10^{10}$ & $4.1 \times 10^{10}$ & $1.3 \times 10^{10}$ \\
\hline & Model & $\mathrm{A} 2$ & $\mathrm{~A} 2$ & $\mathrm{~A} 2$ \\
\hline & $\mathrm{c}$ & 0.25 & 0.27 & 0.25 \\
\hline \multirow[t]{4}{*}{$\mathrm{C}-\mathrm{HCl}$} & $\mathrm{E}(\mathrm{kJ} / \mathrm{mol})$ & 108.2 & 104.6 & 98.7 \\
\hline & $\mathrm{A}\left(\mathrm{min}^{-1}\right)$ & $1.4 \times 10^{10}$ & $1.2 \times 10^{11}$ & $3.8 \times 10^{10}$ \\
\hline & Model & $\mathrm{A} 2$ & A2 & A2 \\
\hline & $\mathrm{c}$ & 0.16 & 0.41 & 0.41 \\
\hline Dev $(\%)$ & & 4.5 & 1.9 & 2.0 \\
\hline
\end{tabular}

$\mathrm{F} 3 *: f(\alpha)=(1-\alpha)^{2.9577} \alpha^{-0.008}$ 
To date, the few kinetic models reported in the literature on the co-pyrolysis of biomass and PVC assumed a single-step co-pyrolysis model and/or first-order reaction mechanism. These assumptions have been shown by several authors to often give inaccurate kinetic parameters. Thus, this work represents a step forward on the determination of kinetic models for co-pyrolysis of biomass and PVC. Furthermore, a key advantage of our model is its relative simplicity, which makes it readily usable in a reactor-scale model of a pyro-gasifier. This latter is crucial for the valorisation of wood waste into valuable products including biomass-derived hydrogen.

Future work will report the exploitation of this model for the pyrolysis/gasification of wood waste at large pilot scale.

Acknowledgments The authors gratefully thank our colleagues at RAPSODEE research centre for technical help.

Funding information The study was financially supported by Suez Environnement (France) and IMT Mines Albi.

\section{References}

1. JRC-IPTS (2010) Study on the selection of waste streams for endof-waste assessment. JRC Scientific and Technical Reports, EUR 24362, https://ec.europa.eu/jrc/en/publication/eur-scientific-andtechnical-research-reports/study-selection-waste-streams-endwaste-assessment-final-report (Accessed August 1 $1^{\text {st }}, 2020$ ).

2. Fail S, Diaz N, Benedikt F, Kraussler M, Hinteregger J, Bosch K, Hackel M, Rauch R, Hofbauer H (2014) Wood gas processing to generate pure hydrogen suitable for PEM fuel cells. ACS Sustain Chem Eng 2(12):2690-2698. https://doi.org/10.1021/sc500436m

3. Pal DB, Chand R, Upadhyay SN, Mishra PK (2018) Performance of water gas shift reaction catalysts: a review. Renew Sust Energ Rev 93:549-565. https://doi.org/10.1016/j.rser.2018.05.003

4. Grande CA (2016) PSA Technology for $\mathrm{H}_{2}$ Separation. In: Stolten D, Emonts B (eds) Hydrogen science and engineering: materials, processes, systems and technology. Wiley-VCH Verlag GmbH \& Co. KGaA, Boschstr. 12, 69469 Weinheim, Germany.

5. Hale SE, Lehmann J, Rutherford D, Zimmerman AR, Bachmann RT, Shitumbanuma V, O'Toole A, Sundqvist KL, Arp HPH, Cornelissen G (2012) Quantifying the total and bioavailable polycyclic aromatic hydrocarbons and dioxins in biochars. Environ Sci Technol 46:2830-2838

6. Zhou H, Long Y, Meng A, Li Q, Zhang Y (2015) Interactions of three municipal solid waste components during co-pyrolysis. J Anal Appl Pyrolysis 111:265-271. https://doi.org/10.1016/j.jaap.2014. 08.017

7. Yu J, Sun L, Ma C, Qiao Y, Yao H (2016) Thermal degradation of PVC: a review. Waste Manag 48:300-314. https://doi.org/10.1016/ j.wasman.2015.11.041

8. Han B, Chen Y, Wu Y, Hua D, Chen Z, Feng W, Yang M, Xie Q (2014) Co-pyrolysis behaviors and kinetics of plastics-biomass blends through thermogravimetric analysis. J Therm Anal Calorim 115(1):227-235. https://doi.org/10.1007/s10973-0133228-7

9. Çepelioğullara Ö, Pütün AE (2013) Thermal and kinetic behaviors of biomass and plastic wastes in co-pyrolysis. Energy Convers Manag 75:263-270. https://doi.org/10.1016/j.enconman.2013.06. 036
10. Miskolczi N, Bartha L, Angyal A (2009) Pyrolysis of polyvinyl chloride (PVC)-containing mixed plastic wastes for recovery of hydrocarbons. Energy Fuel 23:2743-2749. https://doi.org/10. 1021/ef8011245

11. Bai XY, Wang QW, Sui SJ, Zhang CS (2011) The effects of woodflour on combustion and thermal degradation behaviors of PVC in wood-flour/poly(vinyl chloride) composites. J Therm Anal Calorim 91(1):34-39. https://doi.org/10.1016/j.jaap.2011.02.009

12. Sorum L, Gronli M, Hustad J (2000) Pyrolysis characteristics and kinetics of municipal solid wastes. Fuel 80(9):1217-1227. https:// doi.org/10.1016/S0016-2361(00)00218-0

13. Matsuzawa Y, Ayabe M, Nishino J (2001) Acceleration of cellulose co-pyrolysis with polymer. Polym Degrad Stab 71(3):435-444. https://doi.org/10.1016/S0141-3910(00)00195-6

14. Sanchez-Jimnez PE, Prez-Maqueda LA, Perejn A, Criado JM (2013) Generalized master plots as a straightforward approach for determining the kinetic model: the case of cellulose pyrolysis. Thermochim Acta 552:54-59. https://doi.org/10.1016/j.tca.2012. 11.003

15. Aboulkas A, El Harfi K (2009) Co-pyrolysis of olive residue with poly (vinyl chloride) using thermogravimetric analysis. J Thermal Anal Calorim 95(3):1007-1013. https://doi.org/10.1007/s10973008-9315-5

16. Vyazovkin S, Burnham AK, Criado JM, Prez-Maqueda LA, Popescu C, Sbirrazzuoli N (2011) ICTAC Kinetics Committee recommendations for performing kinetic computations on thermal analysis data. Thermochim Acta 520(1-2):1-19. https://doi.org/ 10.1016/j.tca.2011.03.034

17. Burnham AK, Zhou X, Broadbelt LJ (2015) Critical review of the global chemical kinetics of cellulose thermal decomposition. Energy Fuel 29(5):2906-2918. https://doi.org/10.1021/acs. energyfuels.5b00350

18. Sanchez-Jimnez PE, Prez-Maqueda LA, Perejn A, Criado JM (2010) Generalized kinetic master plots for the thermal degradation of polymers following a random scission mechanism. J Phys Chem A 114(30):7868-7876. https://doi.org/10.1021/jp103171h

19. Hu S, Jess A, Xu M (2007) Kinetic study of Chinese biomass slow pyrolysis: comparison of different kinetic models. Fuel 86(17-18): 2778-2788. https://doi.org/10.1016/j.fuel.2007.02.031

20. Wang X, Hu M, Hu W, Chen Z, Liu S, Hu Z, Xiao B (2016) Thermogravimetric kinetic study of agricultural residue biomass pyrolysis based on combined kinetics. Bioresour Technol 219: 510-520. https://doi.org/10.1016/j.biortech.2016.07.136

21. Cagnon B, Py X, Guillot A, Stoeckli F, Chambat G (2009) Contributions of hemicellulose, cellulose and lignin to the mass and the porous properties of chars and steam activated carbons from various lignocellulosic precursors. Bioresour Technol 100:292298. https://doi.org/10.1016/j.biortech.2008.06.009

22. Zhou J, Gui B, Qiao Y, Zhang J, Wang W, Yao H, Yu Y, Xu M (2016) Understanding the pyrolysis mechanism of polyvinylchloride (PVC) by characterizing the chars produced in a wire-mesh reactor. Fuel 166:526-532. https://doi.org/10.1016/j.fuel.2015.11.034

23. Mehl M, Marongiu A, Faravelli T, Bozzano G, Dente M, Ranzi E (2004) A kinetic modeling study of the thermal degradation of halogenated polymers. J Anal Appl Pyrolysis 72(2):253-272. https://doi.org/10.1016/j.jaap.2004.07.007

24. Slopiecka K, Bartocci P, Fantozzi F (2012) Thermogravimetric analysis and kinetic study of poplar wood pyrolysis. Appl Energy 97:491-497. https://doi.org/10.1016/j.apenergy.2011.12.056

25. Hu M, Chen Z, Wang S, Guo D, Ma C, Zhou Y, Chen J, Laghari M, Fazal S, Xiao B, Zhang B, Ma S (2016) Thermogravimetric kinetics of lignocellulosic biomass slow pyrolysis using distributed activation energy model, Fraser-Suzuki deconvolution, and isoconversional method. Energy Convers Manag 118:1-11. https:// doi.org/10.1016/j.enconman.2016.03.058 
26. Davis PJ, Rabinowitz P (2007) Methods of numerical integration, 2nd edn. Dover Publications, Inc., Meneola, New York

27. Marongiu A, Faravelli T, Bozzano G, Dente M, Ranzi E (2003) Thermal degradation of poly(vinyl chloride). J Anal Appl Pyrolysis 70(2):519-553. https://doi.org/10.1016/S0165-2370(03)00024-X

28. De Bruijn TJW, De Jong WA, Van Den Berg PJ (1981) Kinetic parameters in Avrami-Erofeev type reactions from isothermal and non-isothermal experiments. Thermochim Acta 45(3):315-325. https://doi.org/10.1016/0040-6031(81)85091-5

29. Anca-Couce A (2016) Reaction mechanisms and multi-scale modelling of lignocellulosic biomass pyrolysis. Prog Energy Combust Sci 53:41-79. https://doi.org/10.1016/j.pecs.2015.10.002

30. Sanchez-Jimnez PE, Perejn A, Criado JM, Dinez MJ, PrezMaqueda LA (2010) Kinetic model for thermal dehydrochlorination of poly(vinyl chloride). Polymer 51(17):3998-4007. https:// doi.org/10.1016/j.polymer.2010.06.020

31. Miranda R, Yang J, Roy C, Vasile C (1999) Vacuum pyrolysis of PVC I. Kinetic study. Polym Degrad Stab 64(1):127-144. https:// doi.org/10.1016/S0141-3910(98)00186-4

32. Bhargava A, van Hees P, Andersson B (2016) Pyrolysis modeling of PVC and PMMA using a distributed reactivity model. Polym Degrad Stab 129:199-211. https://doi.org/10.1016/j. polymdegradstab.2016.04.016

33. Miranda R, Yang J, Roy C, Vasile C (2001) Vacuum pyrolysis of commingled plastics containing PVC I. Kinetic study. Polym Degrad Stab 72(3):469-491. https://doi.org/10.1016/S01413910(01)00048-9

34. Seshadri V, Westmoreland PR (2014) Role of pericyclic reactions in the pyrolysis of cellulose and hemicellulose. In: Role of pericyclic reactions in the pyrolysis of cellulose and hemicellulose, San Francisco, CA, vol Paper ENFL-133.

35. Seshadri V, Westmoreland PR (2012) Concerted reactions and mechanism of glucose pyrolysis and implications for cellulose kinetics. J Phys Chem A 116(49):11,997-12,013. https://doi.org/10. 1021/jp3085099

36. Bar-Gadda R (1980) The kinetics of xylan pyrolysis. Thermochim Acta 42(2):153-163. https://doi.org/10.1016/0040-6031(80) 87099-7

37. Tran KQ, Bach QV, Trinh TT, Seisenbaeva G (2014) Nonisothermal pyrolysis of torrefied stump - a comparative kinetic evaluation. Appl Energy 136:759-766. https://doi.org/10.1016/j. apenergy.2014.08.026

38. Li Z, Zhao W, Meng B, Liu C, Zhu Q, Zhao G (2008) Kinetic study of corn straw pyrolysis: comparison of two different threepseudocomponent models. Bioresour Technol 99(16):7616-7622. https://doi.org/10.1016/j.biortech.2008.02.003

39. Staggs JEJ (2002) Modelling random scission of linear polymers. Polym Degrad Stab 76(1):37-44. https://doi.org/10.1016/S01413910(01)00263-4

40. Samuelsson LN, Moriana R, Babler MU, Ek M, Engvall K (2015) Model-free rate expression for thermal decomposition processes: the case of microcrystalline cellulose pyrolysis. Fuel 143:438 447. https://doi.org/10.1016/j.fuel.2014.11.079

41. Brown ME (1998) Handbook of thermal analysis and calorimetry: Principles and practice, vol 1. Elsevier, Amsterdam

Publisher's Note Springer Nature remains neutral with regard to jurisdictional claims in published maps and institutional affiliations. 